\title{
Imperialismo e Educação na América Latina: as Conferências Interamericanas de Educação (1943-1963)
}

\section{Imperialism and Education in Latin American: the Inter- American Education Conferences (1934-1963)}

\author{
Fernando César Ferreira Gouvêa \\ Orcid: http://orcid.org/0000-0002-3537-7559 \\ Universidade Federal Rural do Rio de Janeiro, Rio de Janeiro, Brasil, \\ gouveafcf@uol.com.br \\ Leandro Oliveira da Silva \\ Orcid: http://orcid.org/0000-0001-7117-9659 \\ Prefeitura Municipal de Duque de Caxias - Estado do Rio de Janeiro, Brasil, \\ olvrslv@hotmail.com
}

Received on 13/05/2020 - Approved on 15/05/2020

\begin{abstract}
Resumo
O presente trabalho tem por objetivo compreender os fatores determinantes da realização das Conferências Interamericanas de Educação, realizadas entre os anos de 1943 e 1963, fundamentalmente a partir da análise do contexto histórico em que a estratégia diplomática do imperialismo estadunidense estava sob a égide da retórica da cooperação continental, desde a 'Política da Boa Vizinhança' até a celebração do acordo 'Aliança para o Progresso'. Trata-se de uma pesquisa histórica, bibliográfica e documental, assentada nos pressupostos teóricos e metodológicos da história política, sobretudo nas contribuições do movimento dos Annales, que apontou a utilização das Conferências Interamericanas de Educação como instrumento do imperialismo estadunidense para a América Latina.
\end{abstract}

Palavras-chave: Conferências Interamericanas de Educação. Imperialismo. História da Educação Latino-Americana.

\begin{abstract}
This work aims to understand the determinants of the holding of the Inter-American Education Conferences, held between years 1943 and 1963, fundamentally from the analysis of the historical context in which the diplomatic strategy of the american imperialism was under the aegis of the rhetoric of the continental cooperation, from to the 'Good Neighbor Policy' to the signing of the 'Alliance for Progress' agreement. It is a historical, bibliographical and documentary research, based on the theoretical and methodological assumptions of political history, especially on the contribuitions of the Annales movement, which pointed to the use of Inter-American Education Conferences as an instrument of American imperialism for Latin American.
\end{abstract}

Keywords: Inter-American Education Conferences. Imperialism. History of Latin American Education. 


\section{Introdução}

O presente trabalho é resultado parcial de uma pesquisa em andamento e tem por objeto de estudo as Conferências Interamericanas de Educação. Trata-se de uma série de reuniões realizadas entre as décadas de 1940 e 1960 que tinham o objetivo de construir fóruns multilaterais de pactuação de compromissos educacionais entre os Estados Unidos da América (EUA) e os países latinoamericanos, mantendo os países da América Latina sob a zona de influência estadunidense, por meio da retórica de integração das políticas educacionais desenvolvidas nos países da região. A designação 'Conferências Interamericanas de Educação' foi cunhada numa publicação especial do Instituto Nacional de Estudos Pedagógicos ${ }^{1}$, que reuniu o conjunto das recomendações desses encontros (Brasil, 1965).

Como objetivo geral desta pesquisa, propomo-nos compreender os fatores determinantes da realização das Conferências Interamericanas de Educação, fundamentalmente a partir da análise do contexto histórico em que ocorreram, assim como investigar a utilização da educação como instrumento da diplomacia estadunidense na defesa de um projeto societário para os países latino-americanos, alinhados aos interesses dos Estados Unidos. Para tanto, é fundamental analisar os documentos oficiais das reuniões, as suas atas, as recomendações delas decorrentes, os seus acordos e convenções, cotejando-os com o contexto histórico em que ocorreram, sob a perspectiva da análise das relações continentais.

A delimitação do marco temporal da ocorrência das Conferências Interamericanas de Educação, ora tomadas como objeto de estudo, tem como premissa a compreensão de que o período que abrangeu a década de 1930 até o início da década de 1960 marcou um ciclo da política externa estadunidense que pautava como instrumento estratégico de intervenção na América Latina a retórica do respeito à soberania dos países da região, abdicando, em função disso, do emprego de intervenções militares diretas, as quais foram objeto de protestos latinoamericanos nas primeiras décadas do século XX. Neste contexto, dentre outras investidas, a criação de fóruns multilaterais de pactuação de compromissos setoriais foi utilizada como estratégia de promoção da unidade entre os povos americanos sob hegemonia estadunidense, iniciando no período da política externa da 'Boa Vizinhança', passando pelos períodos da indefinição, da negligência hemisférica ${ }^{2}$, até chegarmos aos acordos da Aliança Para o Progresso ${ }^{3}$.

Neste período, encontramos o registro de três reuniões gerais, que estabeleceram um conjunto de recomendações para a educação dos países latinoamericanos, ocorridas em 1943, no Panamá; em 1956, em Lima; e em 1963, em Bogotá. Também registramos uma conferência regional latino-americana, realizada em Lima, no ano de 1956, que tratou especificamente da questão da educação primária, gratuita e obrigatória para a região e, finalmente, uma conferência que tratou da relação entre a educação e o desenvolvimento econômico e social na América Latina, realizada em 1962, em Santiago. Além desses encontros, também incluímos como relevante o estudo de uma reunião extraordinária do Conselho Interamericano Econômico e Social, da Organização dos Estados Americanos $(\mathrm{OEA})^{4}$, ocorrida em Punta Del Este, no ano de 1961, que fixou bases para a adoção de políticas educacionais para a América Latina por meio das recomendações de um Plano Decenal de Educação da Aliança Para o Progresso. 
Trata-se de uma pesquisa histórica, assentada nos pressupostos teóricos da história política. A opção pela utilização dos documentos oficiais dos eventos e a análise crítica deles ocorreu em observância à perspectiva historiográfica anunciada anteriormente e que fundamenta teoricamente o presente estudo.

\section{História Política, Imperialismo e Educação}

Referenciando-nos na compreensão de que a história política é a plataforma teórico-metodológica deste trabalho e tendo em vista que o enfoque de uma pesquisa neste campo é a análise das relações de poder que permeiam os fatos sociais do objeto pesquisado (Barros, 2013, p.106), indicamos ainda, de forma mais específica, que a investigação ora proposta se inscreve na perspectiva teórica da história política renovada a partir da crítica elaborada por historiadores à história política tradicional, especialmente a partir da criação da Escola dos Annales ${ }^{5}$, em 1929, na França.

A crítica dos historiadores da 'nova história política' 6 , designação que passou a ser utilizada para caracterizar o movimento de renovação pelo qual passava a história política no século $X X$, apontava a precariedade das narrativas que privilegiavam e se circunscreviam as ações do Estado e dos grandes personagens políticos e militares como fundamentos das hipóteses explicativas da realidade social e, também, da abordagem que preconizava uma linearidade factual limitada em sua temporalidade, empobrecedora, portanto, da cientificidade do ofício do historiador.

A partir de sua formulação crítica, os historiadores desse movimento de renovação, conscientes da necessidade de contemplar em suas análises de forma dialética o conjunto de elementos que incidem em uma determinada realidade (social, cultural, política e econômica), assim como uma estrutura de temporalidade que articulasse sincrônica e diacronicamente os eventos, propõe o engajamento na busca de uma nova forma da escrita da história. Além da observância desse conjunto de elementos que incidem na realidade social, os historiadores que promoveram debates sobre a necessidade de renovação da perspectiva historiográfica advogaram que a nova forma de escrita da história deveria ser pautada na compreensão de que o passado é sempre tributário de um passado anterior, articulado com os elementos em operação no passado que corresponde ao tempo do objeto e que a análise desse evento no passado deve sempre observar tanto os seus elementos conjunturais quanto os fundamentos estruturais do fato social em análise. Peter Burke nos esclarece tal premissa quando adverte que "os historiadores tradicionais pensam na história como essencialmente uma narrativa dos acontecimentos, enquanto a nova história está mais preocupada com a análise das estruturas" (Burke, 2011, p. 12).

Com relação ao olhar do observador sobre o conjunto dos elementos que incidem numa realidade social na perspectiva da história política, consideramos importante destacar, na presente pesquisa, dois elementos fundamentais: a concepção de Estado e a geopolítica internacional. Por fim, também indicaremos a premissa metodológica norteadora que ora optamos em nossa pesquisa documental.

Se por um lado, a ação política era concebida como ontológica ao ente Estado como ator político e árbitro soberano e imparcial na história política 
tradicional, neste estudo, tomamos como referência a noção de Estado a partir da reformulação crítica da história política que o concebe como uma estrutura política das sociedades contemporâneas em que as suas ações exprimem a correlação de forças que operam numa determinada sociedade. Portanto, há uma dialética nessa concepção de Estado, que tanto o compreende como a instância de máxima organização política de uma sociedade, assim como também se constitui um espaço de disputa entre os grupos que pretendem fazer seus interesses serem representados nesse foro.

$\mathrm{Na}$ medida em que os Estados se desenvolveram a partir dessa interação com a sociedade numa relação dialética, eles também foram assimilando novas atribuições que trouxeram para o campo da história política objetos de estudos outrora desprezados pelas análises políticas tradicionais. É o que nos assegura Rémond.

À medida que os poderes públicos eram levados a legislar, regulamentar, subvencionar, controlar a produção, a construção de moradias, a assistência social, a saúde pública, a difusão da cultura, esses setores passaram, um após outro, para os domínios da história política (Rémond, 2003, p. 24).

Tal premissa é essencial, uma vez que a área de concentração do nosso objeto de estudo é a educação. A educação como área de conhecimento goza de sua autonomia, mas também se articula de forma sistemática com outras áreas, inclusive e fundamentalmente o campo político.

O segundo elemento que destacamos como estrutural é a análise da geopolítica internacional. Como tratamos, anteriormente, um trabalho historiográfico assentado nos pressupostos da renovação da história política supera a ideia do Estado como um ente com vontade própria e o concebe como um território em disputa. Além da disputa de interesses organizados intraestado, as ações do Estado também são forjadas pelas disputas interestados. Segundo Milza (2003, p. 370), ao tratar a questão dessas relações intraestado e interestado no âmbito da história política, "não há diferença de natureza, tampouco separação estanque entre o interior e o exterior, mas interações evidentes entre um e outro, com, entretanto, uma primazia reconhecida do primeiro sobre o segundo".

Dentre as contribuições do autor que nos auxilia a compreender a influência da geopolítica internacional e se estabelecem como fundamentais neste trabalho, destacamos: a relação entre ideologia, política interna e política externa; a geografia e o messianismo de vocação universal.

$\mathrm{Na}$ relação entre ideologia, política interna e política externa, apontamos como elemento fundamental a utilização das conferências como estratégia para pautar nos Estados latino-americanos um projeto educacional que harmonizasse os conflitos internos decorrentes de uma estrutura social e econômica conflagrada e que também assegurasse a estabilidade política da América Latina no período pósguerra. Milza tratou essa estratégia de celebração de pactos em torno de eixos temáticos suprapartidários ressaltando que

A busca do consenso pela política externa, visando a integrar as massas e a transcender as ideologias antagônicas e as lutas partidárias, pode inclinar os estadistas e os grupos dirigentes a propor ao país 'um grande projeto' 
mobilizador cujo objetivo principal é construir a unidade da nação ou preservar a nação, diante do jogo dissolvente das forças centrífugas (Milza, 2003, p. 380).

Ora, a retórica da integração nacional que pretende transcender perspectivas ideológicas e partidárias é, evidentemente, uma ideologia que pretende se estabelecer hegemonicamente. Neste sentido, as Conferências Interamericanas de Educação foram concebidas como estratégias de promoção de projetos educacionais nacionais nas repúblicas americanas, que operaram a partir da lógica da triangulação ideologia - política externa - política interna, em defesa de um projeto de poder no qual subjaz uma perspectiva de mundo.

A "coerção geográfica" apontada por Braudel (2014, p. 50) é uma premissa essencial para estudos do campo político também no contexto das relações internacionais. Tais estudos devem prezar pela relevância da questão geográfica, não apenas nas questões internas dos Estados, mas também em sua localização global. Evidentemente, algumas cautelas devem ser observadas no trabalho do historiador do político no tratamento da questão da geografia para não incidir na armadilha do determinismo geográfico no estudo das relações internacionais. Consciente da complexidade que envolve a incursão em dados geográficos na análise da política externa dos Estados nacionais, considerá-los para fins do estudo que nos propomos é essencial, uma vez que as Conferências Interamericanas de Educação consistem numa estratégia de forjar a organização dos projetos educacionais dos países de uma região exatamente a partir da sua posição geográfica estratégica na zona continental.

O terceiro e último elemento que evocamos para fins de especificar a abordagem que faremos com relação ao aspecto geopolítico é a questão da formação dos processos identitários dos Estados nacionais, no qual a ideia de um messianismo de vocação universal se estabelece como premissa fundamental. Conceitualmente, Milza (2003, p. 371) assegura que o messianismo de vocação universal consiste na "ideia que uma nação faz de suas 'responsabilidades internacionais' e da 'missão' que deve cumprir perante a História (...)". É o conceito de imperialismo que Hobsbawm abordou na "Era dos Impérios" (2018).

O imperialismo é uma categoria essencial na presente pesquisa?. Considerando a conjuntura da ocorrência das Conferências Interamericanas de Educação, na qual se projetava sobre a América Latina a estratégia diplomática estadunidense que apelava para a retórica da cooperação hemisférica e do respeito à autodeterminação dos povos latino-americanos, observamos que a utilização da educação como instrumento diplomático nas relações interamericanas se insere numa ofensiva política e cultural de americanização ${ }^{8}$ da América Latina (Tota, 2000, p. 43).

Finalmente, passaremos a tecer algumas considerações sobre a opção metodológica com relação ao tratamento das fontes. Indicamos, desde já, que trabalhamos com os documentos oficiais ${ }^{9}$ das Conferências Interamericanas de Educação na perspectiva que passaremos a descrever a partir de agora.

As fontes e a forma como elas são tratadas se constituem questões essenciais quando trabalhamos com a história política. O trabalho historiográfico com documentos oficiais foi alvo de agudas críticas dos renovadores da história política, tendo em vista o caráter meramente narrativo que se prestava a historiografia tradicional na leitura dos dados contidos nos documentos. A questão, portanto, não se tratava da fonte documental propriamente dita, mas sim 0 
tratamento que era despendido aos dados. Assim como Le Goff (2013, p. 107) nos assegura que "a história tornou-se científica ao fazer a crítica dos documentos a que se chamava 'fontes"', Peter Burke nos indicou as possibilidades que devem ser exploradas na pesquisa com fontes documentais oficiais, observando que

(...) quando os historiadores começaram a fazer novos tipos de perguntas sobre o passado, para escolher novos objetos de pesquisa, tiveram de buscar novos tipos de fontes para suplementar os documentos oficiais (...). Também se provou possível reler alguns tipos de registros oficiais de novas maneiras (Burke, 2011, p. 25).

Essa releitura dos registros oficiais, que pressupõe a representação da realidade a partir da utilização de novos métodos analíticos e explicativos, estabelece-se como uma possibilidade e um desafio nesta pesquisa. Possibilidade porque se trata da exploração de documentos oficiais que se constituem fontes valiosas e que oferecem uma contribuição relevante para a historiografia educacional brasileira. Desafio porque o ofício do historiador, especificamente no tratamento das fontes documentais, na perspectiva da história política, deve escapar da armadilha que representa a ideia de que os documentos falam por si. Foi exatamente por isso que norteamos nossa análise assentados na premissa de que

O documento não é inócuo. É, antes de mais nada, o resultado de uma montagem, consciente ou inconsciente, da história, da época, da sociedade que o produziram, mas também das épocas sucessivas durante as quais continuou a viver, talvez esquecido, durante as quais continuou a ser manipulado, ainda que pelo silêncio (Le Goff, 2013, p. 497).

Ora, uma vez compreendendo que o documento é a expressão de uma relação de poder, consciente ou não, e que um dos pressupostos que confere cientificidade ao ofício do historiador é exatamente o fato de que ele estabelece uma relação crítica com a sua fonte, na medida em que compreende a necessidade de "ler os documentos nas entrelinhas" (Remónd, 2003, p. 26), observamos ainda que,

Quer se trate de documentos conscientes ou inconscientes (traços deixados pelos homens sem a mínima intenção de legar um testemunho à posteridade), as condições de produção do documento devem ser minuciosamente estudadas. As estruturas de poder de uma sociedade compreendem o poder das categorias sociais e dos grupos dominantes ao deixarem, voluntariamente ou não, testemunhos suscetíveis de orientar a história num ou noutro sentido; o poder sobre a memória futura, o poder de perpetuação, deve ser reconhecido e desmontado pelo historiador. Nenhum documento é inocente. Todos devem ser julgados (Le Goff, 2013, p. 108).

Foi exatamente essa perspectiva da leitura do documento relacionada com as estruturas de poder que operam no contexto da sua produção que referencia 0 presente estudo. Seja esse contexto conjuntural ou estrutural, o que faz confluir a opção metodológica da pesquisa documental com a dimensão teórico-metodológica da história política aqui adotada. 


\section{O Interamericanismo pós-Primeira Guerra Mundial}

A ordem internacional que emergiu após a Primeira Guerra Mundial provou que "o velho mundo estava condenado" (Hobsbawm, 1995, p. 62). Os antigos arranjos sociais, políticos e econômicos, que resultaram na guerra, colapsaram e novos modelos começaram a ser explorados.

Na América Latina não foi diferente. A década de 1920 foi marcada por um processo de profundas transformações políticas, econômicas e sociais na região. No campo político, com o declínio do prestígio do liberalismo evidenciado no colapso europeu, modelos de sistemas políticos alternativos irrompem no cenário, seja com experiências como a russa no leste europeu, seja com a ascensão do nazi-fascismo a oeste do continente. Na economia, a destruição da indústria europeia na guerra e, consequentemente, o enfraquecimento de um importante mercado consumidor dos produtos primários produzidos na América Latina, provocou uma crise no modelo agrário-exportador baseado em monoculturas adotado nos países latino-americanos e a demanda pela diversificação econômica, inclusive, a industrialização dos países da região se tornou uma pauta emergente, mesmo com as elevadas taxas de endividamento que possuíam. Somado a tudo isso, as transformações sociais decorrentes da imigração europeia, da explosão demográfica e do acelerado crescimento das populações urbanas concorreram para a complexificação das estruturas sociais nos Estados latino-americanos, acirrando ainda mais a contestação da política imperialista estadunidense na região.

Nesse contexto, ficou evidenciado o esgotamento da política externa estadunidense para a América Latina adotado desde a virada do século - a política do Big Stick ${ }^{10}$. Nas Conferências Pan-Americanas ${ }^{11}$ da década de 1920, a defesa da "internacionalização da Doutrina Monroe" protagonizada pelos uruguaios (Donghi, 2011, p. 207) e o projeto de "pan-americanização" da União Pan-Americana, proposto pelos delegados costa-riquenhos (Dulci, 2013, p. 65), reverberaram nas demais delegações dos países latino-americanos e se somaram aos protestos antiimperialistas que se acumularam ao longo das primeiras décadas do século $X X^{12}$.

Finalmente, de acordo com Pecequilo (2011, p. 116-117), a Grande Depressão de 1929 e a crise econômica nos EUA e seus impactos mundiais, num cenário de instabilidade na Europa e de transformações das estruturas políticas, econômicas e sociais dos países latino-americanos ${ }^{33}$, corroborou definitivamente para a adoção de uma nova agenda na política externa dos EUA para a América Latina, a 'Política da Boa Vizinhança'.

Segundo Chomsky (2013, p. 21), "a propaganda política está para uma democracia como o porrete está para um Estado totalitário". Se o 'Grande Porrete' estava desgastado, era necessário apelar para outras estratégias. A 'Política da Boa Vizinhança', considerada por muitos autores como a "era de ouro" das relações hemisféricas interamericanistas (Pecequilo, 2011, p. 118), consistiu na reorientação da política externa estadunidense com o objetivo de acomodar as mudanças políticas, econômicas e sociais que ocorriam no sistema internacional e também nos países latino-americanos. Todavia, na prática, a alteração na forma não representou mudanças no conteúdo, conforme nos assegura Moura (1985, p. 18): "os métodos mudaram, mas os objetivos permaneceram os mesmos: minimizar a influência europeia na América Latina, manter a liderança norte-americana e encorajar a estabilidade do continente". 
Sob a égide da Política da Boa Vizinhança, cujos movimentos iniciais podem ser localizados na administração do presidente Herbert Hoover ${ }^{14}$, mas que foi efetivada sob a presidência de Franklin Delano ${ }^{15}$ Roosevelt, Os EUA retiraram suas tropas dos países latino-americanos e abandonaram novas intervenções no continente. Nas Conferências Pan-Americanas da década de 1930, aprovou-se um tratado de não-agressão e conciliação entre as nações do continente (Donghi, 2011, p. 264), com o inesperado apoio da diplomacia dos EUA, evidenciando a estratégia de que os objetivos imperialistas dos EUA seriam perseguidos "pela cooperação e não pela coerção" (Pecequilo, 2011, p. 117). Segundo Ana Luiza Beraba,

A estratégia era forjar, de forma não prepotente, uma 'boa imagem' de 'bons amigos', tanto dos Estados Unidos na América Latina quanto da América Latina nos Estados Unidos. A coesão e a hegemonia continental viriam pela 'camaradagem'. Era importante passar a imagem de que os americanos queriam criar e não explorar (Beraba, 2008, p. 33).

Além das questões políticas e econômicas, um campo de atuação da política externa estadunidense para a América Latina, sob a égide da Política da Boa Vizinhança, que se tornou estratégico para assegurar a hegemonia do país na região foi o imperialismo cultural.

O imperialismo cultural estadunidense na América Latina, no contexto da Política da Boa Vizinhança, consistiu numa ofensiva ideológica nos países da região, a partir de um discurso interamericanista de fraternidade continental, que objetivava afastar a perspectiva reativa nutrida pelos países latino-americanos nos anos da política do Big Stick, superando, paralelamente, a investida ideológica alemã no continente ${ }^{16}$. Para tanto, a estratégia concebia a política de afirmação dos EUA como parceiro estratégico por meio da conquista de corações e mentes dos povos latino-americanos, recorrendo a inundação do discurso de fraternidade continental nos diversos aparelhos da indústria cultural e de formação da opinião pública, tais como a indústria do entretenimento, o rádio, a música, o folclore, a literatura e o jornalismo impresso (Beraba, 2008).

Neste contexto de imperialismo cultural, a educação dos países latinoamericanos também foi considerada uma área de atuação estratégica para os interesses estadunidenses na região. Foi exatamente neste período que ocorreu a primeira reunião interamericana de educação, que deu início a série de encontros que temos por objeto de estudo. Diante disso, passaremos ao tópico seguinte, no qual buscaaremos compreender os fatores históricos determinantes da realização das Conferências Interamericanas de Educação.

\section{As Conferências Interamericanas de Educação: $O$ imperialismo sob a retórica da política de cooperação continental}

Nos marcos da política externa da Boa Vizinhança, um setor considerado estratégico para uma ofensiva politico-ideológica nos países latino-americanos foi exatamente o fomento ao desenvolvimento de suas respectivas políticas educacionais, alinhadas aos interesses estadunidenses. Foi neste contexto que, na iminência do fim do conflito mundial, no ano de 1943, entre os dias 27 de setembro e 04 de outubro, foi realizada a Primeira Conferência de Ministros e Diretores da 
Educação das Repúblicas Americanas, no Panamá. Organizada pela União PanAmericana, a conferência teve como objetivo o estudo dos problemas relativos à educação da América no período pós-guerra. A reunião ocorreu na ocasião da instalação da Universidade Interamericana ${ }^{17}$, instituição cuja criação foi recomendada no relatório da Comissão Especial do Conselho Diretor, da União PanAmericana. Essa Comissão foi instalada exatamente para avaliar a criação de um instituto de cultura e ensino universitário que representasse o desejo de unidade das Américas (União Pan-Americana, 1943a).

A Primeira Conferência de Ministros e Diretores da Educação das Repúblicas Americanas contou com a participação de 21 (vinte e um) países ${ }^{18}$, cuja coordenação esteve a cargo de uma comissão composta por delegados da Colômbia, dos EUA, do Haiti e do Brasil. O representante do Brasil na comissão coordenadora foi o diplomata Paulo Germano Hasslocher. Além dele, compuseram a delegação brasileira: Abgar Renault, Manoel Bergstrom Lourenço Filho e Francisco Clementino San Thiago Dantas. Fundamentalmente, o encontro tinha como objetivo lançar os marcos regulatórios para a criação de uma Universidade Interamericana, conforme deliberado na Comissão Especial do Conselho Diretor, da União PanAmericana, e teve como questões de engajamento prioritárias aspectos que evocavam a ideia de uma origem comum dos povos americanos, a valorização do intercâmbio cultural entre os países do continente e a defesa de sistemas educacionais que promovessem a formação de valores éticos alinhados aos "ideais democráticos da escola americana" (União Pan-Americana, 1943, p. 9).

Com o fim da Segunda Guerra Mundial, após um breve período de indefinição na política externa estadunidense entre os anos de 1945 e 1947, a polarização entre os Estados Unidos e a União das Repúblicas Socialistas Soviéticas (URSS) reocupou o primeiro plano das preocupações internacionais nas décadas que se seguiram ao conflito. Essa clara oposição entre os dois grandes blocos que se estabeleceram no período pós-guerra, sob a liderança dos EUA e da URSS, deu início a um conflito no plano político-ideológico, sem confrontos bélicos diretos entre essas potências, que ficou conhecido como a Guerra Fria. O conflito "dominou o cenário internacional na segunda metade do Breve Século XX” (Hobsbawm, 1995, p. 224), e era caracterizado, fundamentalmente, pelo acirramento da disputa entre dois projetos societários distintos: capitalismo e socialismo.

Dado o acirramento das tensões, provocado pelos indícios crescentes de um futuro conflito de proporções mundiais, a busca pela consolidação da hegemonia política em territórios estratégicos foi perseguida pelas duas grandes potências. Todavia, uma vez considerando que a América Latina estava distante do principal cenário de emergência da Guerra Fria, a atenção da política externa dos EUA se voltou, prioritariamente, para a Europa e para o Pacífico (Pecequilo, 2011, p. 219). Por este motivo, compreendemos que o lapso temporal de treze anos entre a primeira conferência, realizada em 1943, e as iniciativas posteriores, retomadas somente a partir de 1956, seja reflexo desse arrefecimento na política externa estadunidense para a América Latina.

A despeito de iniciativas pontuais no imediato pós-Segunda Guerra que buscavam assegurar o arranjo no sistema hemisférico sob a retórica da manutenção do princípio de cooperação continental, igualdade entre os países americanos e a renúncia às políticas intervencionistas, sobretudo expressas na assinatura do Tratado Interamericano de Assistência Recíproca ${ }^{19}$ e na criação da Organização dos Estados Americanos, foi somente a partir de meados da década de 1950, diante do recrudescimento da insatisfação dos países latino-americanos em decorrência do 
aprofundamento da crise social e econômica na região, que as reuniões sobre educação foram retomadas. Foi neste contexto que, segundo Gouvêa,

[...] o período em tela assistiu à busca de uma atuação regional e conjunta das Américas em diferentes campos. Neste aspecto, uma série de projetos, seminários, congressos e instituições buscaram riscar o céu pan-americano em contraponto às políticas da então União Soviética no contexto histórico da Guerra Fria. (Gouvêa, 2013, p. 1).

A Conferência Pan-Americana de Caracas, realizada em 1954, já dava sinais do processo de inflexão estratégica dos EUA, quando a retórica do resgate dos ideais pan-americanistas foi acionada para o enfrentamento das eventuais investidas soviéticas em território americano. Também ficou evidente o alinhamento institucional da OEA com o projeto imperialista estadunidense, quando o documento final do encontro declarou peremptoriamente que "a atividade comunista na América constituía uma intervenção nos problemas internos americanos" e que "o estabelecimento de um regime comunista em qualquer Estado americano implicava uma ameaça ao sistema" (Donghi, 2011, p. 267). É nesse sentido que Hobsbawm afirma que "a Organização dos Estados Americanos, fundada em 1948, com sede em Washington, não era um corpo inclinado a discordar dos EUA." (Hobsbawm, 1995, p. 352).

Neste contexto, mais uma vez a questão educacional dos países americanos voltou a ser discutida em uma conferência, desta vez convocada pelo Conselho da OEA, tendo sido realizada na cidade de Lima, no Peru, de 03 a 09 de maio de 1956. Além dos vinte e um países que participaram da Segunda Reunião Interamericana de Ministros da Educação, assistiram à reunião, na condição de convidado especial, um observador do Canadá, Sr. Benjamin Rogers, bem como observadores de organismos especializados interamericanos e internacionais e de Organizações nãoGovernamentais internacionais e privadas. A delegação brasileira que participou deste evento foi presidida pelo Ministro da Educação e Cultura, Sr. Clovis Salgado, e tendo como delegados: Antônio Ferreira de Almeida Júnior, Joaquim Moreira de Sousa, Octávio Augusto Lins Martins e Paulo de Almeida Campos. Além deles, também participaram como assessores: Anísio Spínola Teixeira, Antonietta Barone, Oswaldo Coutinho e Adolfo Drubsky (Organização dos Estados Americanos, 1956).

Além deste encontro, entre os dias 23 de abril e 05 de maio, portanto, praticamente concomitante com a realização da Segunda Conferência Interamericana de Educação, foi realizada a Conferência Regional Sobre a Educação Gratuita e Obrigatória na América Latina, promovida pela Organização das Nações Unidas para a Educação, a Ciência e a Cultura (UNESCO) ${ }^{20}$, em colaboração com a OEA, também em Lima, no Peru.

A despeito da retórica de iminente ameaça no continente adotada na Conferência Pan-Americana de Caracas, Donghi assegura que houve o arrefecimento da tensão inicial e a "Guerra Fria parece assumir, em nível mundial, formas novas, menos perigosas que aquelas do período anterior" (2011, p. 314), nas quais as potências que se rivalizavam no conflito passaram a adotar estratégias que tinham como objetivo ações mais efetivas na aproximação com países aliados, de modo que contribuíssem para o desenvolvimento dos mesmos.

No caso específico da América Latina, região de significativo desequilíbrio socioeconômico, a hegemonia estadunidense poderia ser ameaçada, caso a 
negligência hemisférica adota na política externa do país norte-americano desde 1947 fosse mantida. Havia uma demanda objetiva e imperativa: os indicadores educacionais latino-americanos eram compreendidos como um obstáculo ao desenvolvimento econômico da região. Foi para atender essa demanda que houve uma mudança significativa na agenda da conferência realizada na década de 1940, quando comparada com os encontros da década de 1950, pois enquanto a predominância das recomendações da Primeira Conferência de Ministros e Diretores da Educação das Repúblicas Americanas sinalizava para a busca de uma conformação político-cultural com os ideais americanistas, as conferências de 1956 indicaram a necessidade do enfrentamento de um problema estrutural para o desenvolvimento econômico da região - a escolarização primária e a erradicação do analfabetismo ${ }^{21}$. O exemplo brasileiro era paradigmático, pois conforme assegura Romanelli, neste período, era flagrante a "defasagem crescente entre o modelo da educação e o modelo do desenvolvimento" (Romanelli, 2010, p. 195). Fundamentalmente, as reuniões de 1956 indicaram a necessidade de criar mecanismos de superação desse problema por meio de campanhas nacionais de alfabetização e defenderam a importância de que uma ofensiva dessa dimensão deveria ser desenvolvida através de um pacto de cooperação interamericano.

Foi também a partir daí que ficou patente que o desafio de superar os problemas socioeconômicos da América Latina não seria enfrentado de forma eficiente sem o provimento de recursos que financiassem 0 projeto de desenvolvimento econômico da região. Diante dessa constatação, o presidente brasileiro, Juscelino Kubitschek, apresentou ao presidente dos EUA, Dwight Eisenhower, em 1958, um projeto que conciliava a necessidade de desenvolvimento econômico da América Latina com a manutenção da hegemonia estadunidense na região - a Operação Pan-Americana. O programa preconizava investimentos estadunidenses para a solução dos problemas estruturais que se constituíam barreiras ao desenvolvimento dos países latino-americanos. $\mathrm{Na}$ concepção do presidente brasileiro, a implementação da Operação Pan-Americana "permitiria transformar a América Latina numa zona economicamente madura, mantendo-a ao mesmo tempo na esfera internacional dominada pelos Estados Unidos" (Donghi, 2011, p. 316).

Apesar do entusiasmo de países latino-americanos com a proposta apresentada por Kubitschek, a adesão dos EUA não foi imediata. Todavia, após a experiência revolucionária cubana, em 1959, os formuladores da política externa do país norte-americano perceberam a necessidade de considerar o problema do desenvolvimento socioeconômico da América Latina como uma ameaça à estabilidade política regional. Nesta perspectiva, o presidente John Kennedy resgatou o projeto do presidente brasileiro e lançou o programa Aliança Para o Progresso, em seu discurso realizado em 13 de março de 1961, para os embaixadores latino-americanos presentes num encontro na sede do governo dos Estados Unidos.

O lançamento do programa foi uma resposta política aos governos latinoamericanos, na tentativa de manter a hegemonia estadunidense na região, evitando novas rupturas dentro do bloco. Tratou-se de uma iniciativa que previa investimentos dos EUA nos países da América Latina para impulsionar o desenvolvimento da produção local, exigindo, como contrapartida, reformas tributárias com o objetivo de promover o equilíbrio fiscal através da redistribuição da carga tributária. Além disso, o programa previa a realização de reforma agrária para democratizar o acesso à terra e melhorar a produção agrícola através do aperfeiçoamento das técnicas 
utilizadas. Para Kennedy, "tratava-se de uma revolução social pacífica que, no espaço de dez anos, mudaria a face da América Latina" (Donghi, 2011, p. 316).

Neste contexto foram realizadas as três reuniões que também se constituem nosso objeto de estudo: a Reunião Extraordinária do Conselho Interamericano Econômico e Social, da OEA, ocorrida em Punta Del Este, em agosto de 1961, que fixou bases para a adoção de políticas educacionais para a América Latina por meio das recomendações do Plano Decenal de Educação da Aliança Para o Progresso; a Conferência de Educação e Desenvolvimento Econômico e Social na América Latina, realizada em 1962, em Santiago; além da Terceira Reunião Interamericana de Ministros da Educação, realizada em Bogotá, na Colômbia, em 1963.

Assim como os encontros de 1961 e 1962, a Terceira Reunião Interamericana de Ministros da Educação teve como principal temática a adequação do modelo educacional dos países latino-americanos aos ditames das diretrizes do programa econômico que seria adotado para a região, expressas no Plano Decenal de Educação da Aliança Para o Progresso. Com exceção de Cuba, suspensa da OEA em janeiro de 1962 em decorrência dos desdobramentos do processo revolucionário no país, todos os países presentes nas reuniões anteriores também participaram do encontro. A delegação brasileira foi chefiada por Paulo de Tarso Santos, Ministro da Educação e Cultura, tendo como delegados: Olavo Drummond, Guilherme Dutra, Celso Lamprelli, Nailton Santos e Victor José Silveira.

Apesar da recomendação de que as reuniões interamericanas de educação continuassem a ser realizadas periodicamente (Organização dos Estados Americanos, 1963, p.1), não foram encontrados registros de outras reuniões indicando o prosseguimento da realização das Conferências Interamericanas de Educação. Além disso, conforme mencionamos na delimitação do marco temporal que referenciou nossa pesquisa, a partir da década de 1960, houve um esgotamento da retórica da doutrina de fraternidade continental e uma série de golpes de Estado ocorreram na América Latina, inclusive com apoio direto dos Estados Unidos (Pecequilo, 2011, p. 230-231), evidenciando uma nova estratégia na política externa estadunidense para assegurar sua hegemonia na região.

\section{Conclusões}

A partir da análise, foi possível constatar que as Conferências Interamericanas de Educação, realizadas entre os anos de 1943 e 1963, consistiram numa estratégia da diplomacia estadunidense, numa conjuntura em que se privilegiava a afirmação da retórica da cooperação hemisférica, da igualdade entre as nações do continente americano e do princípio da autodeterminação dos povos.

Num primeiro momento, tais encontros tiveram como objetivo fornecer os subsídios ideológicos para a formação de um consenso nos países latinoamericanos em torno da hegemonia regional dos EUA. Foi nesta perspectiva que a Primeira Conferência de Ministros e Diretores da Educação das Repúblicas Americanas priorizou em sua pauta aspectos que fomentavam a identidade originária comum dos povos americanos, a promoção do intercâmbio cultural e de políticas educacionais alinhadas com os ideais americanistas.

Finalmente, na medida em que a retórica da 'Boa Vizinhança' apresentou sinais de esgotamento e o bloco de oposição à liderança dos Estados Unidos na América Latina no contexto da Guerra Fria passou a ser concebido pelos 
formuladores da política externa estadunidense uma alternativa de desenvolvimento viável e que poderia ser desejável pelos países da região, a pauta dos encontros passou a assimilar demandas estruturais da educação latino-americana, tais como o problema da escolarização primária universal e, sobretudo, na perspectiva de subordinação dos projetos educacionais nacionais ao plano de desenvolvimento econômico alinhado aos interesses dos EUA na região.

\section{Referências}

Barros, J. D’a. (2013). O campo da História: especialidades e abordagens. Petrópolis: Vozes.

Beraba, A. L. (2008). América Aracnídea: teias culturais interamericanas. Rio de Janeiro: Civilização Brasileira.

Brasil. (1965). Ministério da Educação e Cultura. Instituto Nacional de Estudos Pedagógicos. Conferências Interamericanas de Educação. Rio de Janeiro: INEP/MEC.

Braudel, F. (2014). Escritos sobre a História. - 3 Ed. São Paulo: Perspectiva.

Burke, P. (2010). A Escola dos Annales (1929-1989): a Revolução Francesa da historiografia. -2 ed. São Paulo: Editora da UNESP.

Burke, P. (2011) Abertura: a nova história, seu passado e seu futuro. In: Burke, P. (org.) A escrita da história: novas perspectivas. São Paulo: Editora UNESP, 7-38.

Chomsky, N. (2013) Mídia: propaganda política e manipulação. São Paulo: Editora WMF Martins Fontes.

Donghi, H. (2011). História da América Latina. - 4 ed., 1 Reimp. - São Paulo: Paz e Terra.

Dulci, T. M. S. (2013). As Conferências Pan-Americanas (1889 a 1928): identidades, união aduaneira e arbitragem. - São Paulo: Alameda.

Gouvêa, F. (2018). Anísio Teixeira e o Conselho de Educação Superior nas Repúblicas Americanas: cooperação ou intervenção? São Paulo: Paco.

Gouvêa, F. (2013). O Conselho de Educação Superior para as Repúblicas Americanas: um voo para além do céu Pan-Americano. In: Congresso Brasileiro de História da Educação, 7., 2013, Cuiabá. Anais eletrônicos... Cuiabá: UFMT, 2013. Recuperado de: <http://sbhe.org.br/novo/congressos/cbhe7>. Acesso em 21 set. 2017.

Hobsbawm, E. (1995). Era dos Extremos: o breve século XX, 1914-1991. - 2 ed. 57 Reimpressão. - São Paulo: Companhia das Letras.

Hobsbawm, E. (2018). Era dos Impérios: 1975-1914. Rio de Janeiro/São Paulo: Paz e Terra.

Le Goff, J. (2013). História e Memória. - 7 ed. - Campinas: Editora UNICAMP.

Milza, P. (2003). Política Interna e Política Externa. In: Rémond, R. (org.) Por uma história política. - 2. ed. - Rio de Janeiro: Ed. FGV. p. 365-399.

Moura, G. (1985). Tio Sam chega ao Brasil - A penetração cultural americana - 2 ed. - São Paulo: Editora Brasiliense. 
Organização dos Estados Americanos. (1956). Ata Final da Segunda Reunião Interamericana de Ministros da Educação. Lima: OEA.

Organização dos Estados Americanos. (1956a). Anexo 'B' da Ata Final da Segunda Reunião Interamericana de Ministros da Educação: Conferência Regional Sobre La Educacion Gratuita Y Obligatoria en America Latina. Lima: OEA.

Organização dos Estados Americanos. (1961). Aliança para o Progresso: Documentos oficiais emanados da Reunião Extraordinária do Conselho Interamericano Econômico e Social no Nível Ministerial. Punta del Este: OEA.

Organização dos Estados Americanos. (1962). Provisional Report of the Conference on Education and Economic and Social Development in Latin American. Santiago: OEA.

Organização dos Estados Americanos. (1963). Ata Final da Terceira Reunião Interamericana de Ministros da Educação. Bogotá: OEA.

Pecequilo, C. S. (2011). A política externa dos Estados Unidos. - 3. Ed. ampl. e atual. - Porto Alegre: Editora da UFRGS.

Rémond, R. (2003). Uma História Presente. In: Rémond, R. (org.) Por uma história política. - 2a . Ed. Rio de Janeiro: Ed. FGV, p. 13-36.

Romanelli, O. (2010). História da Educação no Brasil. 36 ed. - Petrópolis: Vozes.

Santos, L. C. V. G. (2004). O Brasil entre a América e a Europa: O Império e o Interamericanismo (do Congresso do Panamá à Conferência de Washington). São Paulo: Editora UNESP.

Tota, A.P. (2000) O Imperialismo Sedutor: a americanização do Brasil na época da Segunda Guerra. São Paulo: Companhia das Letras.

União Pan-Americana. (1943) Acta Final de la Primera Conferencia de Ministros y Directores de Educación de las Repúblicas Americanas. Panamá: União PanAmericana.

União Pan-Americana. (1943a). Conselho Diretor. Ata da Sessão Ordinária realizada a 3 de maio de 1943. Washington: União Pan-Americana.

\section{Notas}

\footnotetext{
${ }^{1}$ O Instituto Nacional de Estudos e Pesquisas Educacionais Anísio Teixeira é uma autarquia federal, atualmente vinculada ao Ministério da Educação, que declara ter como função a produção de dados para subsidiar a implementação de políticas educacionais. Foi criado em 1937 e, na ocasião da publicação especial sobre as Conferências Interamericanas de Educação, o nome da instituição era Instituo Nacional de Estudos Pedagógicos. Informações disponíveis no site do órgão, no endereço eletrônico <http://portal.inep.gov.br/web/guest/inicio $>$. Acesso em 02 de mai. 2020.

2 Segundo Pecequilo (2011, p. 219), logo após os anos de parceria entre os Estados Unidos e a América Latina, no período da política da 'Boa Vizinhança' (1933-1945), a política externa estadunidense "foi marcada por uma relativa indecisão", entre os anos de 1945 e 1947. A partir de 1947, até o ano de 1959, houve "um crescente desinteresse dos Estados Unidos pela região". A América Latina voltou a se tornar um palco do teatro estratégico de maior atenção para o país norteamericano após a Revolução Cubana, em 1959.

${ }^{3}$ A Aliança para o Progresso foi um pacto multilateral celebrado pelos EUA com os países da América Latina, em resposta à deterioração da hegemonia continental estadunidense, baseada na premissa da "cooperação hemisférica", com o objetivo de coibir a influência da União das Repúblicas Socialistas Soviéticas (URSS) na região, num contexto de Guerra Fria, por meio de investimentos
} 
para promover o desenvolvimento dos países latino-americanos e "para atingir metas de progresso e reestruturação social, política e econômica" (Pecequilo, 2011, p. 228-229).

${ }^{4}$ A Organização dos Estados Americanos é um organismo multilateral regional, criada no ano de 1948, na Conferência de Bogotá, na Colômbia. Atualmente congrega 35 (trinta e cinco) países americanos e na declaração de propósitos da instituição, expressa ter como objetivo fundamental o desenvolvimento do sistema interamericano. Site da Instituição disponível em $<$ http://www.oas.org/pt/>. Acesso em 02 de mai. 2020.

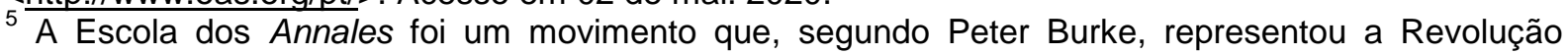
Francesa da historiografia, tendo como marco inicial a criação do periódico francês Annales d'histoire économique et sociale, em 1929, que após algumas alterações em sua denominação, ficou conhecida como a Revista dos Annales. De modo geral, foi um movimento que concorreu significativamente para a ampliação das possibilidades de análises históricas e do desenvolvimento da historiografia (Burke, 2010)

${ }^{6}$ Cabe aduzir que, neste trecho da tese, utilizamos a palavra 'nova' por se tratar do momento do surgimento de um enfoque diferente dos anteriores para a História e, consequentemente, para a história política. No tempo presente, a palavra 'nova' não faz mais sentido.

7 Duas premissas foram estruturantes na configuração das relações diplomáticas dos EUA com a América Latina ao longo da história: a primeira representada na Doutrina Monroe e a segunda na tradição que subsidiou a política do Destino Manifesto. A primeira representava uma tradição da política externa estadunidense na defesa da América para os americanos, que, segundo nos esclarece Tota (2000, p. 36), tais americanos para os estadunidenses são os "do Norte". Já a sobre a política do Destino Manifesto, Pecequilo (2011, p. 59) nos assegura que a mesma partia da premissa de "que a expansão territorial representava um direito divino dos Estados Unidos de se espalhar por toda a América do Norte, com apoio de Deus para a conquista, pois ela possibilitaria levar a liberdade e a democracia a locais em que ainda não existiam". Ainda de acordo com a autora, tais tradições se estabeleceram estruturalmente na perspectiva diplomática estadunidense, uma vez que ela considera que "o passado é um patamar a partir do qual podemos refletir sobre a real natureza desse país e os caminhos que escolheu para si mesmo no mundo, de acordo não somente com seus interesses, mas em resposta às demandas de seus valores e de seu espírito como nação" (Pecequilo, 2011, p. 33).

${ }^{8}$ A expressão "americanização" foi aqui utilizada no sentido apontado por Tota (2000, p. 36). O autor descreveu que a utilização da expressão "americanos" pelos nascidos nos EUA refletia "(...) um desejo inconsciente, que se traduzia na ideia do 'destino manifesto': os Estados Unidos se apropriaram da palavra América para designar o país". Neste sentido, o autor (2000, p. 19) nos assegura que a reelaboração doutrinária da política externa dos EUA para a América Latina, mediada pela Política da Boa Vizinhança', ressignificou o "americanismo, entendido aqui como uma ideologia programática, em que o sufixo -ismo tinha se transformado num poderoso armamento intencional, com o claro objetivo de suplantar outros -ismos, autóctones ou não. A Americanização foi o processo de implantação dessa ideologia nas 'culturas mais débeis' da América Latina".

9 Os documentos oficiais foram obtidos mediante consulta nos arquivos virtuais da Columbus Memorial Library, órgão responsável pela memória institucional da OEA, assim como pela política de acesso à informação da instituição. Site da Instituição disponível em <http://www.oas.org/en/columbus/>. Acesso em 01 de mai. 2020.

${ }^{10}$ O Cololário Roosevelt à Doutrina Monroe, também conhecida como a Política do 'Big Stick', foi uma inflexão na retórica da política externa estadunidense que representou, na prática, a oficialização do intervencionismo político, econômico e militar dos EUA nos países latino-americanos que, embora já ocorresse desde a vitória na Guerra Hispano-Americana, ganhou escala significativa até os anos 1930. Segundo Peter Smith (1996, apud Pecequilo, 2011, p. 91), entre 1898 e 1934, foram registradas mais de trinta intervenções militares estadunidenses na América Latina.

${ }^{11}$ As Conferências Pan-Americanas foram um instrumento da política externa estadunidense para a América Latina e foram realizadas entre os anos de 1889 e 1948, totalizando nove encontros. Essas reuniões se constituem uma base fundamental para analisarmos as relações hemisféricas na concepção da doutrina imperialista. Mais detalhes sobre as Conferências Pan-Americanas em Luís Cláudio Villafañe Gomes Santos (2004) e Maria Tereza Spyer Dulci (2013).

${ }_{12}$ Sobretudo os protestos sob a liderança das delegações argentinas (Dulci, 2013).

${ }^{13}$ Hobsbawm (1995, p. 109-110) faz uma síntese dos impactos da Grande Depressão em países da América Latina.

${ }^{14}$ Herbert Hoover foi o trigésimo primeiro presidente dos Estados Unidos, cuja administração ocorreu entre os anos de 1929 e 1933.

${ }^{15}$ Sucessor de Helbert Hoover, que presidiu os EUA de 1933 até a sua morte, ocorrida em 12 de abril de 1945.

${ }^{16}$ Segundo Boris Fausto, "a Alemanha iniciou uma política de influência ideológica e de competição com seus rivais na América Latina" (2015, p. 324). Sobre essa estratégia alemã, Gerson Moura nos 
esclarece que, "além de jogar com afinidades entre movimentos e partidos políticos latinoamericanos, a propaganda germânica mobilizava uma bateria de agências oficiais e informais embaixadas, consulados, empresas comerciais, linhas aéreas, agências distribuidoras de notícias, clubes, etc, - para criar simpatia e até mesmo difundir os valores emanados do nacional-socialismo" (Moura, 1985, p. 14). Convém destacar ainda que, embora a experiência vitoriosa russa seja vista pelos estrategistas da política externa estadunidense como uma ameaça para a estabilidade da hegemonia do país norte-americano na América Latina, Donghi (2011, p. 255) nos assegura que "a guerra (Segunda Guerra Mundial) forma um complicado intermezzo, até o momento em que a Guerra Fria virá novamente delimitar os campos, de modo cada vez mais urgente, após ter sido o sistema interamericano - sobretudo por meio da ação direta dos Estados Unidos - transformado num instrumento dessa Guerra Fria".

${ }_{17}$ Durante a conferência, foi aprovado o Estatuto da Universidade Interamericana, cuja sede seria a Universidade do Panamá, e que se propunha a ser um "centro de cultura superior interamericano, símbolo da unidade espiritual e moral das Américas" (União Pan-Americana, 1943,p. 30).

${ }^{18}$ Países que participaram da Primeira Conferência Interamericana de Educação: Haiti, Paraguai, República Dominicana, Uruguai, El Salvador, Brasil, Cuba, Honduras, EUA, Bolívia, México, Colômbia, Guatemala, Venezuela, Panamá, Equador, Argentina, Chile, Nicarágua, Peru e Costa Rica. ${ }^{19} \mathrm{O}$ Tratado Interamericano de Assistência Recíproca consiste num pacto de segurança dos EUA com a América Latina que "estabelece o compromisso entre todas as nações do hemisfério de se unirem para repudiar ataques a membros da aliança, estabelecendo o conceito de solidariedade hemisférica" (Pecequilo, 2011, p. 220).

${ }^{20}$ A UNESCO foi criada em 1945, logo após a Segunda Guerra Mundial, com o objetivo declarado de promover a causa educacional, da ciência e da cultura como forma de garantia da integração entre os povos e a paz mundial.

21 Dados apresentados no encontro apontavam para 14 milhões de crianças sem escolas e 45 milhões de adultos analfabetos nos países americanos (Organização Dos Estados Americanos, 1956, p. 11). 